\title{
Wechat Service of University Library under the Mode of 020 Reading Promotion
}

\author{
Lina Li \\ Library of Heilongjiang Bayi Agricultural University, Daqing, China \\ Email: byndcscy@126.com
}

How to cite this paper: Li, L. N. (2020). Wechat Service of University Library under the Mode of O2O Reading Promotion. Advances in Journalism and Communication, $8,49-58$.

https://doi.org/10.4236/ajc.2020.82004

Received: May 13, 2020

Accepted: June 13, 2020

Published: June 16, 2020

Copyright (c) 2020 by author(s) and Scientific Research Publishing Inc. This work is licensed under the Creative Commons Attribution International License (CC BY 4.0).

http://creativecommons.org/licenses/by/4.0/

(c) (i) Open Access

\begin{abstract}
This paper systematically sorts out the current situation of WeChat service in the field of university library in order to promote the orderly and indepth development of WeChat service in university library. By investigating and analyzing the Wechat service of 42 university libraries which have won the "National Reading Demonstration Base" in China, the author points out the problems in the use of Wechat service in reading promotion of University Libraries in China, such as the lack of standardization in the setting of public number, the weak interaction between WeChat public number platform readers and backstage staff, and the insufficient development of the reading promotion column on WeChat public number platform. This paper points out the development direction of university library reading promotion using WeChat public number platform. In order to provide meaningful reference for other university libraries to improve the quality of reading promotion.
\end{abstract}

\section{Keywords}

University Library, Reading Promotion, National Reading, Wechat Service

\section{Introduction}

Libraries are the repository of knowledge and the center of literature and information in Colleges and universities (Zhou et al., 2019). They play an important role in personnel training and cultural inheritance. With the development of new media technology, the service means of libraries are also undergoing tremendous changes. As the distributing center of literature information resources, university library plays an irreplaceable role and advantages in promoting reading. In the new era, under the digital trend of new media reading media, reading promotion is facing new opportunities and challenges (Zhang \& Li, 2019). In particular, WeChat public platform has gradually become the most popular so- 
cial network platform, and the number of active users keeps increasing. The powerful functions of WeChat can meet students' personalized reading needs anytime and anywhere. Adopting diversified reading promotion activities is not only an innovation of traditional reading promotion, but also can improve the effect and quality of promotion services ( $\mathrm{Li}, 2018$ ). The combination of university library and WeChat public platform can bring personalized service function, real-time interactive experience and economic operation cost, and provide continuous support and guarantee for the reform of reading promotion (Zhou, 2019). The WeChat service of the library is to carry out the reader service work through the WeChat public account platform (Ren \& Li, 2019). The university library was the first to open the WeChat service in the library community. On November 5, 2012, Beijing international studies university was the first to open the WeChat public account platform, which opened the WeChat service era of university libraries in China.

$\mathrm{O} 2 \mathrm{O}$ is called Online to Offline, that is, Online to Offline or from online to offline, and it is a business model originated from the United States. In 2013, O2O realized the integration and improvement of mobile devices. As a generally accepted marketing model, it was quickly cited by other industries (Di et al., 2017). In 2014, Wang Kangning introduced the O2O model into the research of library science for the first time, and explored the future development direction of library by referring to the transformation experience of Suning Corporation. In 2015, Sun $\mathrm{Yu}$ and related scholars conducted a research on university library service based on $\mathrm{O} 2 \mathrm{O}$ model. In 2015, Tong Ziyi first discussed the application of $\mathrm{O} 2 \mathrm{O}$ model in library reading promotion service. Thus it can be seen that the $\mathrm{O} 2 \mathrm{O}$ model has opened a new way for the reading promotion of university libraries.

Based on the investigation and analysis of WeChat services of 42 university libraries which have won the title of "national reading demonstration base", this paper summarizes the current situation and existing problems of WeChat services in university libraries when they carry out reading promotion work, and puts forward corresponding solutions, so as to improve the quality of WeChat services.

\section{Research Ideas and Data Sources}

\subsection{Research Objects}

This study focuses on the methods and effects of university library WeChat public platform as a way of reading promotion service. This study selects 42 university libraries that have won the "national reading demonstration base". Based on the WeChat public platform, this paper investigates the service of university library's WeChat public platform, finds out the existing problems, and proposes valuable Suggestions to promote the better development of university library's online reading promotion.

\subsection{Data Collection}

In order to obtain relevant data, the following survey methods were adopted: 
firstly, the WeChat public number of the university library which was awarded the "national reading demonstration base" was paid attention to, and then the mobile services provided by the WeChat platform were investigated through practical operation. Browse the title column of the official account at all levels, and record the mobile service content and the layout of the column of the official account. When it is not possible to obtain information directly from the column layout, it will further obtain data by WeChat public number message and search historical news and other auxiliary ways.

\section{Investigation and Analysis}

\subsection{Survey Results}

\section{1) WeChat public account opening status}

By using the WeChat APP's built-in public account search function and Sogou WeChat search function, we searched the WeChat public accounts of 42 university libraries that won the title of "national reading demonstration base", and manually collected the Wechat IDs that opened the Wechat public account and pushed the articles. Up to April 17, 2018, after a search and telephone counseling, except the library of Beijing University of Posts and Telecommunications, Guangxi University of Science and Technology library, Library of Huanghuai college, Beijing University of Agriculture library, a total number of 38 universities library opened WeChat public account, WeChat account opening rate reached $90.48 \%$, visible WeChat service is very important in reading promotion work in colleges and universities.

\section{2) WeChat public account type}

At present, the WeChat public account types provided by Tencent Holdings Ltd include service account, subscription account, enterprise WeChat and small procedures. According to the survey, the library of Southwest Jiaotong University has two WeChat public accounts, one service account and another subscription account. Eleven libraries, including the library of Huaibei Normal University and the library of Inner Mongolia University of Science and Technology, use service accounts, accounting for $28.2 \%$ of the total. The other 28 university libraries use subscription accounts, accounting for 71.8 percent of the total.

\section{3) WeChat public account naming}

According to the survey, the WeChat public account naming method of 31 university libraries is "school name + library", accounting for $79.5 \%$ of the total.

The second naming method is referred to as "school abbreviation + library", this naming method has four universities, accounting for $10.3 \%$ of the total number, The WeChat public accounts are respectively: Zhonggong library (Zhongyuan University of Technology library), Southwest Jiaoda University library (Southwest Jiaotong University library), Shengda college library (Shengda Trade Economics \& Management College library of Zhengzhou) and Fujian Shida library (Fujian Normal University library).

The third naming method is personalized naming, this naming method includes 
four universities, accounting for $10.3 \%$ of the total number, WeChat public accounts are respectively: Jianda library (Beijing University of Civil Engineering and Architecture library), Hexi library (Hexi College library), South post Shulinyi (library of Nanjing University of Posts and Telecommunications) and Zheshi graphic (library of Zhejiang Normal University).The author did not find the WeChat public accounts of the above-mentioned four university libraries on the WeChat APP, so it is necessary to search the Sogou WeChat search engine for the text and text messages published by the above units, and search for the information of the WeChat public accounts according to the content in the text and text messages.

4) WeChat public account icon

Among the opening IDs of the 39 WeChat public accounts, twenty-four (accounting for $61.5 \%$ ) public accounts use library icon as the public account icon, nine (23.1\%) public accounts use library buildings as the public account icon, there are six (15.4\%) public accounts adopt other personalized image as the public icon, such as the library and the library of Nanjing normal university, Renmin University of China use artistic words, University of Electronic Science and Technology of China library uses artistic buildings, library of Nanjing university of posts and telecommunications uses publications, the library of Wuhan university uses the mascot, and Southwest Jiaotong University library's service has no Wechat public account icon.

\section{5) The QR code setting of library website WeChat public account}

During the research process, besides the following five official websites malfunction of Beijing University of Civil Engineering and Architecture library, Huaibei Normal University library, National Open University, Nanyang Normal University library, Zhongyuan University of Technology library, 14 library websites have no WeChat public account QR code scanning function, 19 library's official website have no WeChat public account QR code. Some libraries' official websites also have yet no mobile library, microblog, QQ and other mobile service functions.

\section{6) Reply function usage status}

\section{a) Automatic reply for the first follow}

For the first follow, only the WeChat official accounts of Hunan university library and Peking University library did not use the automatic reply function for the first follow. For the first follow, the rest of the 37 WeChat public accounts' auto reply are respective: welcome (14), thanks to (7), welcome phrases with keyword function introduction (9), welcome phrases with book retrieval introduce (2), welcome phrases with a library card information introduction (1), welcome phrases with binding introduction (1), thanking phrases with keyword function introduction (1), function introduction (1), multi-graphic news (1).

\section{b) Automatic reply to messages}

In the 39 researched WeChat public account platforms, The author left the message "Dear editor, I am a library staff from Heilongjiang Bayi Agricultural 
University (HLAU), we are doing a survey, what time does your prestigious unit register the WeChat public account?", the library of Beijing University of Civil Engineering and Architecture, Huaibei normal university library, Inner Mongolia University of Science and Technology and other $20 \mathrm{WeChat} \mathrm{public} \mathrm{accounts}$ did not auto reply message. The rest of the 19 WeChat public accounts auto reply message as following: keyword function introduction (7), courtesy reply (5), thanks phrases (1), thanking phrases with keyword function introduction (2), thanking phrases and polite reply (1), the announcement on recent important things (1), welcome phrases with a library card information introduction (1), a book to introduce (1). In addition to polite reply, the library of Sichuan University automatically identifies the name of the individual WeChat. In addition to introducing the functions of key words, the reply from Renmin University of China library also includes the application of geographical location sharing.

\section{7) Customized menu}

The customized menu can effectively enrich the WeChat public account page, so that users can better understand the functions of the public account and facilitate users to use the WeChat public account.

\section{a) Primary menus}

The management of WeChat public account platform stipulates that each WeChat public account can set 3 primary menus. According to the statistics of 39 WeChat official accounts, there are no customized menus in the library of Beijing University of Civil Engineering and Architecture, and there are 113 menus in the library of Tsinghua University. In the statistical analysis, "resource services" respectively belong to the resource category and the service category, so 115 analysis data are obtained.

Among the $38 \mathrm{WeChat}$ public accounts with level 1 menus, $32 \mathrm{WeChat}$ public accounts have a primary menu of service, accounting for $84.2 \%$. The main function of university library WeChat public account platform is the service function, and some scholars put forward the concept of WeChat service. There are 27 WeChat public accounts with "my library" primary menu, accounting for $71.1 \%$. Another function of university library WeChat public account platform is mobile library or mobile phone library, which is convenient for readers to use various library collection resources. There are 17 WeChat public accounts with resource class menu, accounting for $44.7 \%$. The most important point for readers to use the library is the library's resources. Therefore, the introduction of various resources is set on the mobile terminal, which not only facilitates readers to use the various resources of the library, but also effectively promotes and promotes various resources. There are $12 \mathrm{WeChat}$ public accounts with a reading primary menu, accounting for $31.6 \%$. There are $12 \mathrm{WeChat} \mathrm{public} \mathrm{accounts} \mathrm{with} \mathrm{perso-}$ nalized first-level menus, which are aimed at college students in the new era and readers born after 1990 and 2000. How to attract them to use WeChat platform is the most important work of each library. Therefore, in terms of menu setting, some schools use more personalized menus. There are 8 WeChat public ac- 
counts, accounting for $26.7 \%$, with information primary menu. Another function of WeChat public account platform is the push of all kinds of notifications and information, so some schools choose to use this function in the menu together. There are $7 \mathrm{WeChat}$ public accounts with a primary menu of search/guide, accounting for $10.5 \%$. The setting of the guidebook menu has solved all kinds of events that readers urgently need to know and are not able to come to the library. The setting of this menu has effectively solved the problem that novice readers can effectively use the Internet library and obtain effective information.

\section{b) Secondary menu}

Tencent officially stipulates that each primary menu can set a maximum of 5 secondary menus, theoretically each public account can have a maximum of 15 secondary menus. Data collection was conducted on 38 public accounts with customized menus, and a total of 472 secondary menus were collected.

There are 13 public accounts with 15 secondary menus, accounting for $34.2 \%$. The second one is the public accounts with 13 secondary menus, which is 7 , accounting for $18.4 \%$. Most of the units in the secondary menu Settings, choose a large number of, covering a wide range of ways to meet the needs of readers, readers can also be more convenient to use WeChat public account. However, some schools choose concise Settings. For example, the number of secondary menu Settings on WeChat public account of Tsinghua university library is only 3 , while the number of secondary menu Settings on WeChat public account of University of Electronic Science and Technology of China is 5.

In the setting of the secondary menu, in order to avoid the constraint of the five secondary menu Settings, some units choose to use the jump function, that is, through the jump function can be directly connected to the richer content of the page. There were 5 public accounts that chose such Settings, accounting for 13.2\%. The library of Hunan Normal University used two jump functions, and the library of University of Electronic Science and Technology of China, library of Northeast Normal University, library of Fujian Normal University and library of Central South University all used one jump function.

In terms of the selection of secondary menu contents, the top three are collection inquiry category (33), borrowing/renewal category (30), binding/unbinding category of reader's card (28), notification/announcement category (20) and seat reservation category (11).

\subsection{Existing Problems}

1) Standardization lack of WeChat public account name Settings

At present, the naming methods of opened WeChat public account are mainly three kinds, "school name + library", "school abbreviation + library" (Wang, 2017) and personalized naming. "School name + library" is a relatively standard naming method, which is convenient for readers to search the public account. "school abbreviation + library" is aimed at users who are familiar with the school, and the degree of aspects is as the first, but for those users who are relatively un- 
familiar with the school, this method is not applicable to the public account search. Although personalized naming is innovative and special, it is not conducive to the promotion of WeChat public account.

2) The interaction between readers and backstage staff of WeChat public account platform is weak

As for the message questions related to 2.6 (2), only 5 WeChat public accounts have replied. The library of Tsinghua University has the fastest reply speed, while the library of University of Science \& Technology Beijing (USTB) has the most complete reply content. In addition to the important research content, there are polite terms in the reply information.

3) Insufficient development of WeChat public account platform reading promotion column

With the development of the "new normal" of reading promotion, the work of reading promotion has been on a par with the library's most historical borrowing service and resource service. According to the survey results, most of the major functions of the WeChat public account platform are book borrowing services and library entry services. The content and form are not innovative, which are not much different from the traditional library services. In terms of reading promotion services, we mainly focus on good book recommendation, new book newsletter and training seminar. Secondly, it is the promotion of digital resources, such as blog reading micro magazine, blog reading aloud, super star digital reading, QQ reading, new Oriental classroom, cloud image sound, etc. The school characteristics will be only a few school reading promotion activities in WeChat menu, such as Hunan Normal University library stack room, Renren reading, elegant normal university library, art storeroom, reading a school book, live little black house, figure all series, etc., the knowledge of the world in Peking University library, the 120th library ceremony cards, such as the Xiaobu love letter in the library of Wuhan university, etc.

\section{Suggestions}

\subsection{Improve the Platform Marketing Efforts}

The library's WeChat public account platform can be combined with the reading promotion activities to attract readers to pay attention to the library's WeChat platform and actively participate in the reading promotion activities by taking advantage of the WeChat platform's built-in voting and other functions. Taking Heilongjiang Bayi Agricultural University (Bayi Nongda) library carried out in 2017 on the "masters of my opinion, essay contest" activities as an example, in the library open a vote channel WeChat public platform, called for the readers to vote for an ideal work in your own mind, which by message traffic for 2705 times, created the record high traffic. In order to improve the effective reading rate of WeChat graphic messages, a book review activity is set up in the column of recommendation of good books, which not only carries out online activities, but also enhances the attention of WeChat platform. 


\subsection{Improve the Construction Level of the Platform}

The library should cultivate a high-quality, characteristic and efficient WeChat platform operation team, and establish and improve the supervision and management system to ensure the efficiency and security of information release (Fei, 2018). At the same time, the operation team of WeChat platform should strengthen their own business learning and training on the use of cutting-edge technologies, so as to improve the production level of graphic messages. Some funds can also be invested in the daily maintenance of the platform and the motivation and commendation of team members.

\subsection{Enrich the Activities Content on the Platform}

WeChat public account platform takes text, picture, sound, video and other media as the way for information transmission, providing basic conditions for online reading promotion activities. The WeChat public account platform is applied to reading promotion activities, such as diversified forms of guided reading, reading method guidance, reading promotion activities, etc. (Lou, 2014), so as to cultivate readers' interest in reading and subtly guide and educate readers. In addition, the public platform is also an effective way for readers to participate in the interaction, consultation and feedback of reading promotion activities. Therefore, the content of activities on WeChat platform should be enriched to facilitate the transmission of information and enhance the affinity of reading promotion.

\subsection{Establish a People-Oriented Concept}

At present, college students are all born in the 90 s and 00 s, and they all have a strong sense of rights safeguarding and individuality (Yang et al., 2015), which brings new challenges to the work of college reading promotion. All the reading promoters are thinking about how to make the work of reading expansion enter the hearts of readers. The information push and colorful online activities on WeChat public account platform not only help the university library's reading promotion activities to form a relaxed, sunny and upward image of being close to the people, but also are easy to be accepted by readers and interact and participate from the heart. Reading promotion workers can use the WeChat public account platform to launch solicitation and research activities among readers, which can not only arouse readers' sense of ownership, but also fully reflect the openness of university library construction and development and the democratic nature of reading promotion. Doing readers' own reading activities and carrying out reading activities that readers like will be the development trend of university library reading promotion.

\subsection{Build the Brand Image of the School}

The school-running characteristics and brand image of colleges and universities directly affect the source of students and teaching quality of colleges and univer- 
sities. There is a positive correlation between the reading atmosphere of students and the quality of education in colleges and universities. Through the information release on the library WeChat account platform and the development of reading promotion activities, it can intuitively reflect the basic situation of a school and the status of students. The WeChat public account platform is not only a channel for internal information transmission and a position for effective communication, but also a window for external publicity. Through the brand shaping of WeChat public account platform, it will be developed into a veritable mobile university library.

\section{Conclusion}

With the rapid development of information technology and the innovation of Web2.0 technology in the field of library, the university library WeChat public platform service, as a favorite of new media, can better promote the dissemination of knowledge, and its entry into the university library is also the trend of the contemporary education service system. The extensive use of new media technology has brought opportunities and challenges to the promotion of university reading, and has also made it an environment and carrier that university libraries increasingly cannot ignore. As one of the new media with the highest amount of readers' use and attention, the development, construction and application of WeChat public account platform is of great practical significance for establishing and spreading the brand image of colleges and universities, expanding the way of reading literacy education and creating a good reading atmosphere. Only by participating in readers' daily knowledge exchange and integrating into readers' life and study can the library truly improve readers' sense of identity to the library, enhance the influence of the library in the school, and win the support for further development (Le, 2018). In the future, by constantly analyzing the development trend of user information behavior and combining with the continuous development of multimedia technology, further optimizing the technology, function and service design of WeChat platform, a more scientific and reasonable decision will be made for the construction research of university library WeChat public platform based on user information behavior (Xu, 2019).

\section{Funding}

This paper is a research projects of Periodical achievement of the reading promotion project of Chinese library society: "study on rural cultural construction boosted by university library reading promotion from the perspective of rural vitalization strategy" (Project Number: YD2018B29); Heilongjiang Provincial Department of Culture Provincial Art Planning Project "Research on Cultural Construction in Rural Revitalization Strategy" (Project Number: 2018D024).

\section{Conflicts of Interest}

The author declares no conflicts of interest regarding the publication of this paper. 


\section{References}

Di, C. S., Zhang, X. M., \& Guo, S.M. (2017). "Internet+" Background “O2O” WeChat University Library Service Mode Study. Journal of intelligence Science, 10, 133-137.

Fei, L. L. (2018). Micro Reading in University Library under the New Media Environment Service Platform Construction and Promote Research. Changchun: Jilin University.

Le, S. S. (2018). University Library WeChat Marketing-Zhejiang University Library as an Example to Present Study. Journal of University of Book Intelligence Journal, 2, 62-67.

Li, Q., \& Han, J. Y. (2018). A Study on the Evolution of the Mode of Reading Promotion in Chinese University Libraries. Library and Information Service, 22, 5-14.

Lou, G. (2014). “985” WeChat Public Platform in University Library Present Situation Investigation and Analysis. Journal of China Press, 4, 34-36.

Ren, Y. Y., \& Li, G. H. (2019). A Study on the Operation Strategy and Application of Library Reading Promotion Activities. Journal of the National Library of China, 6, 21-30.

Wang, C. Y. (2017). University Library Marketing Strategy Based on WeChat Platform Research. Harbin: University of Heilongiiang.

Xu, R. Q. (2019). Discussion on the Mechanism of Sustainable Development of University Library Reading Promotion. Inside and Outside Lantai, 31, 45-46.

Yang, J. M., Li, X. M., \& Wu, Z. Y. (2015). WeChat Public Platform Application in University Students' Management Work-Work in Heilongjiang August First Land Reclamation University Undergraduate Students is the Official WeChat Patients. Journal of Daqing Academy of Social Sciences, 4, 103-106.

Zhang, H. D., \& Li, G. H. (2019). The Influence of Reading Experience on the Dissemination Effect of University Library Reading Promotion. Journal of the National Library of China, 6, 54-65.

Zhou, J., Liu, Z., Liu, H. T. et al. (2019). An Empirical Study on "Reading Promotion+" Evaluation in Universities Based on EBL-Taking the Library of Liaoning Normal University as an Example. Library Research, 6, 90-98.

Zhou, Y. N. (2019). Chengcai in Luojia Books with Youth-Wuhan University Library Reading Promotion Practice. Library Work in Colleges and Universities, 5, 58-61. 